\title{
Estudo comparativo do uso do dispositivo intra-uterino inserido no pós-parto/pós-cesárea imediatos
}

\section{Comparative study of the use of the intrauterine device inserted in the immediate postpartum/post-cesarean section period.}

\author{
Autor: Ana Lúcia Letti Müller \\ Orientador: Prof. Dr.José Antonio de Azevedo Magalhães \\ Co-orientador: Prof. Dr.José Geraldo Lopes Ramos
}

Dissertação de Mestrado apresentada no Programa de Pós-Graduação em Medicina: Ciências Médicas da Universidade Federal do Rio Grande do Sul, em 22 de novembro de 2004.

Objetivo: comparar o uso e as taxas de expulsão do DIU inserido no pós-parto e no pós-cesárea imediatos. Métodos: foi realizado um ensaio clínico para avaliação do uso do DIU inserido no puerpério imediato, (19 pacientes pós-parto vaginal e 19 pacientes pós-cesárea) no Hospital de Clínicas de Porto Alegre - RS - Brasil. Foi utilizado o DIU T de cobre 380-A. Com a intenção de identificar dispositivos deslocados sem a percepção clínica, foram efetuados controles com ultra-sonografia transvaginal, realizada com um mês e entre 3-12 meses de intervalo após a inserção. Foram considerados expulsos os DIUs que se encontravam fora da cavidade endometrial (no canal endocervical) no exame ultrasonográfico ou fora do útero, sem considerar a distância do dispositivo e a parede uterina. O exame clínico foi realizado após a ultra-sonografia, para correlacionar a expulsão ultra-sonográfica com a clínica, através da visualização do dispositivo deslocado. Resultados: a taxa de expulsão encontrada foi diferente entre os grupos. No grupo pós-parto a expulsão foi de 50\% (9 casos vistos pela ultra-sonografia somente) mais $27,8 \%$ (3 casos vistos pela ultra-sonografia e confirmados com exame clínico mais duas expulsões completas do DIU para fora do útero). No grupo pós-cesárea não ocorreram expulsões. A diferença estatística encontrada foi significativa, com um p < 0,001 (Odds Ratio 5,75 - Intervalo de Confiança 95\% 2,36 - 14,01). Conclusão: Considerando que a eficácia contraceptiva do DIU se deva à sua posição intracavitária, a alta taxa de expulsão no grupo pós-parto vaginal impossibilita seu uso nesta situação. A inserção do DIU pós-cesárea permanece como uma alternativa viável, visto que a taxa de expulsão neste grupo foi nula. O controle da inserção pela ultrasonografia foi mais completo, pois o exame clínico falhou para verificação em $75 \%$ dos casos de expulsão ocorrida na inserção pós-parto (9 de 12 casos).

PALAVRAS-CHAVE: Dispositivo intra-uterino; Inserção pós-placentária; Ultra-sonografia transvaginal

KEYWORDS: Intrauterine device; Post-placental insertion; Transvaginal ultrasound

Resumo de Tese

\section{Câncer de mama, menopausa e qualidade de vida}

\section{Breast cancer, menopause, and quality of life}

Autor: Délio Marques Conde

Orientador: Prof. Dr. Aarão Mendes Pinto-Neto

Co-orientador: Prof. Dr. César Cabello dos Santos

Tese de Doutorado em Tocoginecologia, apresentada ao Departamento de Tocoginecologia da Faculdade de Ciências Médicas da Universidade Estadual de Campinas, em 23 de março de 2005.

Objetivos: comparar a prevalência de sintomas climatéricos, a proporção de mulheres com atividade sexual e a qualidade de vida (QV) em mulheres com e sem câncer de mama e identificar os fatores associados à $\mathrm{QV}$ em mulheres com câncer de mama. Métodos: realizouse estudo de corte transversal em que foram incluídas 97 mulheres com câncer de mama e 85 sem câncer de mama, com idade entre 45 e 65 anos, não usuárias de terapia hormonal ou tamoxifeno nos últimos seis meses. A QV foi avaliada por meio do questionário Medical Outcomes Study 36-item Short-Form Health Survey (SF-36). O modelo generalizado linear permitiu identificar os fatores associados à QV. Resultados: a média de idade foi de 53,2 $\pm 6,2$ e de $57,8 \pm 4,9$ anos para mulheres com e sem câncer de mama, respectivamente ( $\mathrm{p}<0,01)$. Mulheres com câncer de mama relataram menos atividade sexual $(51,5 \%)$ do que mulheres sem câncer $(62,4 \%)$ (p <
0,01). O componente capacidade funcional da QV apresentou mediana dos escores de 90 para o grupo com câncer e de 75 para o grupo sem câncer ( $<<0,01)$. Sintomas climatéricos, ser casada, pós-menopausa e cirurgia conservadora de mama associaram-se negativamente à $\mathrm{QV}$ de mulheres com câncer de mama. Conclusões: a prevalência de sintomas climatéricos foi similar em mulheres com e sem câncer de mama. A QV foi boa em mulheres com e sem câncer de mama, porém mulheres com neoplasia maligna de mama apresentaram melhor capacidade funcional. Foram identificados fatores que se associaram negativamente à $\mathrm{QV}$ e que representam eventos comuns na vida da mulher (sintomas climatéricos, ser casada, pós-menopausa).

PALAVRAS-CHAVE: Mama: câncer; Qualidade de vida; Menopausa; Climatério 